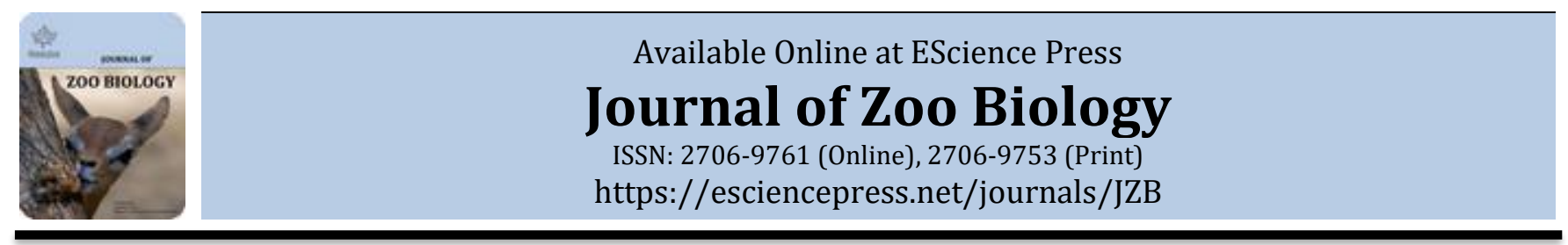

\title{
INVESTIGATIONS ON DIFFERENT SEMEN EXTENDERS FOR COCKATIEL SEMEN
}

\author{
aHelena Schneider*, aDominik Fischer, bKlaus Failing, 'Christine Ehling, \\ dSabine Meinecke-Tillmann, eAxel Wehrend, aMichael Lierz \\ a Clinic for Birds, Reptiles, Amphibians and Fish, Faculty of Veterinary Medicine, Justus Liebig University Giessen, \\ Frankfurter Str. 91, 35392 Giessen, Germany. \\ b Unit for Biomathematics and Data Processing, Faculty of Veterinary Medicine, Justus Liebig University Giessen, \\ Frankfurter Str. 95, 35392 Giessen, Germany. \\ ${ }^{c}$ Friedrich-Loeffler-Institut, Federal Research Institute for Animal Health, Institute of Farm Animal Genetics, Hoeltystr. \\ 10, 31535 Neustadt, Germany. \\ ${ }^{d}$ Department of Reproductive Biology, University of Veterinary Medicine Hannover, Buenteweg 2, Hannover, Germany. \\ e Clinic for Obstetrics, Gynecology and Andrology of Large and Small Animals, Faculty of Veterinary Medicine, Justus \\ Liebig University Giessen, Frankfurter Str. 106, 35392 Giessen, Germany.
}

*Corresponding Author Email: helena.Schneider@vetmed.uni-giessen.de

\section{A B S T R A C T}

The aim of the present study was the modification and evaluation of three different semen extenders for cockatiel semen in order to achieve a long survival time for transport, examination purpose and for potential cryopreservation, respectively. Therefore, individual and pooled semen samples of 30 cockatiels (Nymphicus hollandicus) were investigated for $\mathrm{pH}$ and osmolality values and subsequently $\mathrm{pH}$ and osmolality values of the semen extenders were adjusted to those values in the semen. Pooled semen samples were then partitioned into four equal parts and diluted with the three different semen extenders in 1:4 and 1:8 dilution. 1\% glucose-Ringer's solution was used as control, respectively. A total of 64 incremental diluted semen samples were obtained for investigation. Each dilution was investigated regarding sperm motility immediately after dilution and another four times every 30 minutes. Sperm viability was evaluated 0 and 120 minutes after dilution via eosin B-stain on the diluted semen samples and in pure semen samples. Additionally, the fluorescence stain SYBR® Green/propidium iodide was used to assess sperm viability. The results indicate that cockatiel spermatozoa are highly sensitive to variations in $\mathrm{pH}$ and osmolality, requiring adjustment of commercial diluents to $\mathrm{pH}=7.42$ and osmolality $=300 \mathrm{mOsm} / \mathrm{kg}$. Modified Lake diluent maintained higher viability and motility than other diluents tested. Sperm morphology was indicated to be least adversely affected by modified Lake diluent in 1:4 concentration compared to other semen extenders and concentrations used.

Keywords: psittacine spermatozoa, parrots, semen analysis, sperm motility, assisted reproduction.

\section{INTRODUCTION}

More than one third of all psittacine species are listed as threatened by the International Union for Conservation of Nature and Natural Resources (IUCN 2014). The main risk and cause of this decline is, apart from illegal trade and slight clutch size in some species, the steadily progressing loss of habitat (Snyder et al. 2000, Wright et al. 2001). Captive breeding programs have been demonstrated as important tools for species conservation (Collar and Butchart 2014) using assisted reproduction (AR) to improve the breeding success
(Blanco et al. 2009, Lierz et al. 2013, Fischer et al. 2014a). Assisted reproduction includes semen collection and artificial insemination (AI) which have been practiced effectively in domestic fowl for almost 80 years (Quinn and Burrows 1936) but experiences in AR in psittacine birds are scarce. Artificial insemination has been described in cockatiels (Neumann et al. 2013), budgerigars (Samour 2002) and some larger parrot species (Brock 1991, Lierz et al. 2013, Fischer et al. 2014a) but up to now AI in psittacines is mostly only possible with fresh semen (Brock 1991, Neumann et al. 
2013). However, fresh semen cannot be stored for a prolonged period of time to overcome transport or seasonal dependences. To preserve physiological properties and functions of spermatozoa during storage the composition of the semen extender (SE) is fundamental (Salamon and Maxwell 2000). An appropriate diluent has to provide an energy source for spermatozoa and maintain $\mathrm{pH}$ and osmolality levels preferably identical to those of seminal plasma, the natural medium for sperm (Siudzinska and Lukaszewicz 2008, Blanco et al. 2012). Diluents should be able to compensate eventual pH-value deferrals caused by sperm metabolic products through their buffering capacity. Osmolality can also affect sperm function as low osmolality values cause the spermatozoa to swell when water is drawn into the cells, whereas in a hyperosmotic solution, spermatozoa lose water and shrink (Bakst 1980). Important parameters for the evaluation of a semen extender are the assessment of total motility (MOT) and progressive motility (PMOT) as well as the percentage of viable and morphological normal spermatozoa (MNS) (Fischer et al. 2014b). These parameters enable the estimation of long-term storage of spermatozoa and fertilization following AI (Froman 2000, Blesbois et al. 2008). Semen extenders have been studied in the domestic fowl and diluents such as Lake diluent (Lake and Stewart 1978) and Beltsville Poultry Semen Extender (BPSE) (Sexton 1977) are commercially available for poultry. Turkey semen diluted with Beltsville Poultry Semen Extender has been demonstrated to be less deteriorated during short time storage $(3 \mathrm{~h})$ at $5{ }^{\circ} \mathrm{C}$ compared to Lake diluent, although no significant differences in motility, viability and membrane integrity have been confirmed (Iaffaldano et al. 2010). Other findings demonstrated a positive influence on the survival and motility of crane and turkey spermatozoa through supplementation of $0.1 \mathrm{M}$ betaine hydrochloride and $30 \mathrm{mM}$ adenosine triphosphate (ATP) (Blanco et al. 2011). Extenders in domestic fowl are the basis for studies on semen extenders for non-domestic birds due to the lack of species specific studies, especially in psittacines. In budgerigars, Lake diluent and modified Biggers, Whitten and Whittinghams medium have been evaluated (Samour et al. 1988) whereas in cockatiels 1\% glucoseRinger's solution $(1 \% \mathrm{G})$ demonstrated best results in PMOT in comparison with five other semen extenders after a storage time of 120 minutes (Stelzer 2004). Lake diluent has also been used as a semen extender in Hispaniolan parrots (Amazona ventralis) prior to AI (Brock 1991). However, only one study exists on the evaluation of semen extenders with psittacine semen over a defined period of time (Stelzer 2004).

The aim of the present study was to modify semen extenders for cockatiel semen in order to achieve an appropriate dilution for dependable short and long time semen storage. Cockatiels were chosen as model animals for psittacines due to their almost year-round seasonality (Arndt 1996) so that semen can be collected quite reliably through the established massage method. Moreover, basic spermatological data are available for this species (Fischer et al. 2014b) and AR techniques have been applied successfully before (Neumann et al. 2013). This study should be a first step towards an efficient protocol for cryopreservation of psittacine semen which may be easily modified for large parrots.

\section{MATERIALS AND METHODS}

Cockatiels and semen collection: In this study, 30 healthy, male, two to four year old cockatiels were randomly selected out of a breeding flock and clinically examined. All birds were experienced breeding birds, which were paired with female birds and had produced fertile clutches in previous breeding seasons. Good body condition score (BCS 3 or 4 on a scale of 1 to 5) and absence of infectious agents (Chlamydia sp., Candida sp., parrot bornavirus, avian polyomavirus, psittacine circovirus, paramyxovirus $1 \& 3$ and endoparasites) were attested to all birds. The cockatiels were marked with colored legbands and housed in three separated indoor ( $3 \times 2.4 \times 2.4 \mathrm{~m})$ - outdoor ( $3 \times 2.5 \times 2.5 \mathrm{~m}$ ) combined aviaries placed in their original flock. Ambient temperature in the indoor aviaries was approximately $21{ }^{\circ} \mathrm{C}$ and a photoschedule of 13:11 LD assisted by artificial light (Arcadia $20 \mathrm{~W}$ Fluorescent Bird Lamp, 2,4\% UVB / 12\% UVA; Arcadia Products plc, Redhill, United Kingdom) was applied. Nest boxes were offered in all aviaries to stimulate nesting activity. Water was offered ad libitum. Birds were fed a commercial, mineral supplemented cockatiel diet plus fresh fruits and vegetables in the morning.

Semen was collected once a week during the months of February to November using a massage method as described before (Neumann et al. 2013). Briefly, the birds were manually restrained in dorsal recumbency by an assistant and the cloaca was cleaned with tissues if faecal contamination was visible. Thumb and index 
finger of the examiner were positioned on both sides of the cloaca and the middle finger dorsally near the uropygial gland. Gentle opposed rhythmic movements of the thumb and index finger for approximately 30 seconds induced the ejaculation. If no active ejaculation could be evoked, semen could yet be massaged out of the deferent duct if present. Semen was then collected in a graduated microcapillary tube (Wiretrol ${ }^{\circledR}$ II 1 to $5 \mu \mathrm{l}$, Drummond Scientific Co, Broomall, PA, USA).

This study was conducted in accordance with national laws and the methods were approved by the competent regional authority (Regierungspraesidium) Giessen, Germany, with the permission number GI 18/9 No. 07/2012.

\section{Semen analysis and adjustment of semen extenders} Initial semen analysis and osmolality measurements: Collecting the semen in a microcapillary tube permitted evaluation of volume, semen color, sperm density and estimated sperm motility. Until investigation, individual samples were stored in a cool box filled with cold water $\left(+4{ }^{\circ} \mathrm{C}\right)$. Constancy of temperature was verified by a digital thermometer. Only semen samples without macroscopically visible contamination of feces and urates were used for analysis. Sperm density and motility were evaluated immediately after semen collection by placing the microcapillary tube onto a slide using a Leica DM2500 microscope (Leica Mikrosysteme Vertrieb GmbH, Wetzlar, Germany) and X 100 magnification. A pre-estimation of the amount of spermatozoa was performed by grading sperm density inside the capillary from 0 to 5 (0: no spermatozoon per visual field, 1: 1 to 20 spermatozoa per visual field, 2: 21 to 100 spermatozoa per visual field, 3: 101 to 200 spermatozoa per visual field, 4: > 201 spermatozoa per visual field, 5: not countable). Sperm motility in the microcapillary tube was subjectively estimated and classified from 0 to 4 by judging the velocity of spermatozoa heading towards the liquid/air barrier $(0$ : no movement, 1: slow, 2: sedate, 3 : at pace, 4: extremely fast).

The $\mathrm{pH}$-value was then measured from a small drop of semen $(\leq 0.5 \mu \mathrm{l})$ out of individual samples by using indicator test-strips (Spezialindikatorpapier, pH 5.5 9.0; 5.4 - 7.0 \& 6.4 - 8.0; Macherey-Nagel GmbH \& co. KG, Dueren, Germany). Sperm concentration was assessed in 100 fold diluted (distilled water) semen in a Neubauer improved counting chamber and total sperm count was calculated by multiplication of the sperm concentration with the semen volume (Behncke 2002).

For osmolality measurement, semen of cockatiels was pooled in an Eppendorf ${ }^{\circledR}$ Safe-lock microcentrifuge tube (Eppendorf AG, Hamburg, Germany) by adding non contaminated individual samples until a volume of at least $100 \mu \mathrm{l}$ was reached. Samples were cooled to $+4{ }^{\circ} \mathrm{C}$ until measurements were performed approximately 60 minutes after collection with a semi-micro osmometer (Loeser Osmometer Typ 6, Loeser Messtechnik, Berlin, Germany). The measurements were performed according to the manufacturer's specifications in nine replicates in order to achieve statistically sound values.

Adjustment of semen extenders: Three semen extenders, Lake diluent (SE 1) (Lake and Stewart 1978), a semen extender described by Blanco et al. (SE 2) (Blanco et al. 2008) and Beltsville Poultry Semen Extender (SE 3) (Sexton 1977), were prepared with modifications to the original formula by dissolving the chemicals in water for injection (Wasser fuer Injektionszwecke, Serumwerk Bernburg AG, Bernburg, Germany). All used chemicals were obtained from Sigma ${ }^{\circledR}$ Life Science as BioXtra or BioUltra products and were dissolved without heating. $\mathrm{PH}$ and osmolality values of the solutions were measured (S20 SevenEasy $^{\mathrm{Tm}} \mathrm{pH}$, Mettler Toledo GmbH, Giessen, Germany; Loeser Osmometer Typ 6, Loeser Messtechnik, Berlin, Germany) and adjusted accordingly to $\mathrm{pH}=7.42$ by addition of $1 \mathrm{M} \mathrm{NaOH}$ or 1 $\mathrm{M} \mathrm{HCl}$ solution and to osmolality $=300 \mathrm{mOsm} / \mathrm{kg}$ by varying the amount of soluble substances (for final composition see Table 1). Glucose solution 1\% (Ringer Loesung B. Braun Ecoflac ${ }^{\circledR}$ plus \& Glucose 5\% B. Braun Ecoflac ${ }^{\circledR}$ plus, B. Braun, Melsungen AG, Melsungen, Germany) was used as control according to previous studies and not adjusted to the mentioned values to assure better comparability. All solutions were sterilefiltered (Millex® Syringe Filter Units, $0.22 \mu \mathrm{m}, 33 \mathrm{~mm}$, Merck Millipore, Merck KGaA, Darmstadt, Germany) and bottled in small portions of each $10 \mathrm{ml}$ into sterile tubes (CELLSTAR $\AA$ TUBES, Greiner Bio-One GmbH, Frickenhausen, Germany). Until use, the modified semen extenders were stored at $-22{ }^{\circ} \mathrm{C}$. To SE 2 , ATP was added immediately before dilution of the pooled semen sample. The semen extenders were refrozen immediately after use. 
Table 1. Components of different semen extenders after adjustment to $\mathrm{pH}$ and osmolality (except for $1 \% \mathrm{G}$ ).

\begin{tabular}{|c|c|c|c|c|c|c|c|c|}
\hline \multicolumn{2}{|c|}{$1 \% \mathrm{G}^{\mathrm{a}}$} & \multicolumn{2}{|c|}{ SE $1^{b}$} & \multicolumn{3}{|c|}{$\mathrm{SE} 2^{\mathrm{c}}$} & \multicolumn{2}{|c|}{ SE $3^{d}$} \\
\hline constituent & $(\mathrm{ml})$ & constituent & weight (g) & constituent & weight (g) & molarity & constituent & weight (g) \\
\hline $\begin{array}{l}\text { Ringer's } \\
\text { solution }\end{array}$ & 4 & D-fructose & 0.70 & D-fructose & 0.575 & & D-fructose & 0.333 \\
\hline \multirow[t]{7}{*}{$\begin{array}{c}\text { Glucose } \\
\text { solution } 5 \%\end{array}$} & 1 & $\begin{array}{l}\text { sodium } \\
\text { glutamate }\end{array}$ & 1.92 & $\begin{array}{l}\text { sodium } \\
\text { glutamate }\end{array}$ & 2.00 & & $\begin{array}{l}\text { sodium } \\
\text { glutamate }\end{array}$ & 0.578 \\
\hline & & $\begin{array}{l}\text { magnesium } \\
\text { acetate } \\
\text { (tetrahydrate) }\end{array}$ & 0.08 & $\begin{array}{l}\text { potassium } \\
\text { acetate } \\
\text { (anhydrous) }\end{array}$ & 0.25 & & $\begin{array}{l}\text { sodium } \\
\text { acetate } \\
\text { trihydrate }\end{array}$ & 0.287 \\
\hline & & $\begin{array}{l}\text { potassium } \\
\text { acetate } \\
\text { (anhydrous) }\end{array}$ & 0.50 & $\begin{array}{l}\text { betaine } \\
\text { hydrochloride }\end{array}$ & & $0.1 \mathrm{M}$ & $\begin{array}{l}\text { potassium } \\
\text { citrate }\end{array}$ & 0.0427 \\
\hline & & $\begin{array}{l}\text { polyvinyl- } \\
\text { pyrrolidone } \\
\text { (MW 10,000) }\end{array}$ & 0.30 & $\begin{array}{l}\text { polyvinyl- } \\
\text { pyrrolidone } \\
\text { (MW 10,000) }\end{array}$ & 0.15 & & $\begin{array}{l}\text { magnesium } \\
\text { chloride } \\
\text { hexahydrate }\end{array}$ & 0.0227 \\
\hline & & & & $A T P$ & & $30 \mathrm{mM}$ & $\begin{array}{l}\text { dipotassium } \\
\text { hydrogen } \\
\text { phosphate }\end{array}$ & 0.8467 \\
\hline & & & & & & & $\begin{array}{l}\text { potassium } \\
\text { dihydrogen } \\
\text { phosphate }\end{array}$ & 0.0433 \\
\hline & & & & & & $\begin{array}{l}\mathrm{N} \text {-tris (Hyc } \\
\text { methyl-2-a } \\
\text { sulfonic aci }\end{array}$ & $\begin{array}{l}\text { xy-methyl) } \\
\text { loethane }\end{array}$ & 0.195 \\
\hline
\end{tabular}

Bold italic font indicates modification from original formula. Dilute in sterile water and dissolve to $100 \mathrm{~g}$.

Abbreviations: G, glucose-Ringer's solution; SE, semen extender. a based on (Stelzer 2004) bbased on (Lake and Stewart 1978) ${ }^{\mathrm{c}}$ based on (Blanco et al. 2008) d based on (Sexton 1977).

Evaluation of semen extenders: All evaluations were performed by a single investigator with proven intraobserver reliability and experiences in semen analysis for more than two years. Investigated and pooled semen samples were partitioned into four aliquots and diluted $1: 5$ with $1 \% \mathrm{G}$ as a control and three different modified semen extenders Lake diluent, Blanco and BPSE (SE 1 3) in 1:4 and 1:8 dilution, respectively. $30 \mathrm{mM}$ ATP was added to SE 2 shortly before mixing with the semen sample to reveal possible positive effects on cockatiel spermatozoa motility and survival. Each semen extender in each dilution was evaluated at least eight times regarding sperm motility, viability and morphology which results in a total of 64 investigations including the samples diluted with $1 \% \mathrm{G}$.

Motility assessment: Sperm motility was checked manually after $0,30,60,90$ and 120 minutes by pipetting $8 \mu \mathrm{l}$ of the semen/diluent mixture onto a slide, covering it with a cover slip and counting the spermatozoa in a defined area of each 5 visual fields as previously described (Fischer et al. 2014b). They there classified into non-motile and motile spermatozoa (MOT), whereby forward progression (PMOT), local motility and circular motility were differentiated.
Motility was not evaluated in pure samples as they were too dense to differentiate between the individual spermatozoa and motility may have been altered by high interspermatozoal interferences. Between the evaluation times samples were stored in a cool box filled with cold water at $+4{ }^{\circ} \mathrm{C}$.

Viability assessment: Viability stains were made of pure semen samples and semen compounded with the different diluents after 0 and 120 minutes $(0 \mathrm{~min}=$ immediately after mixing). For staining eosin B $2 \%$ and the fluorescence stain SYBR ${ }^{\circledR}$ Green/propidium iodide (LIVE/DEAD ${ }^{\circledR}$ Sperm Viability Kit; Invitrogen ${ }^{\mathrm{TM}}$, Molecular Probes ${ }^{\mathrm{TM}}$, Eugene, OR, USA) were used according to previous studies (Fischer et al. 2014b). Briefly, $2 \mu$ of semen were mixed with eosin B $2 \%$ on a glass slide, incubated for 15 seconds and smeared according to standard procedures (WHO 2010). In the dried smear 200 spermatozoa per slide were evaluated. Thereby dead spermatozoa (colored) were distinguished from live spermatozoa (unstained or white) and subsequently a live/dead ratio was calculated.

Furthermore $5 \mu \mathrm{l}$ of semen were added to $2.5 \mu \mathrm{l}$ of the SYBR® Green/propidium iodide solution prepared as specified by the manufacturer and incubated at room 
temperature for 10 minutes in a brown microfuge tube to protect the reagents from light. $7 \mu \mathrm{l}$ of the mixture were then pipetted onto a slide, covered with a cover slip and evaluated at X 400 magnification with a fluorescence microscope with a fluorescent light source (Leica DM2500; Leica Mikrosysteme Vertrieb GmbH, Wetzlar, Germany). Green spermatozoa were interpreted as live sperm cells (excitation: $488 \mathrm{~nm}$, emission: $516 \mathrm{~nm}$ ), red spermatozoa were counted as dead sperm cells (excitation: $530 \mathrm{~nm}$, emission: $617 \mathrm{~nm}$ ).

Morphologic evaluation of spermatozoa: A morphologic evaluation of 200 spermatozoa in the eosin B smear was performed at X 1000 magnification using oil immersion with a Leica DM2500 microscope (Leica Mikrosysteme Vertrieb GmbH, Wetzlar, Germany). Spermatozoa were classified into morphologic normal and abnormal spermatozoa. The different abnormalities were further classified according to a detailed description previously published on gander spermatozoa (Marvan et al. 1981), which had been used in psittacine semen samples before (Behncke 2002, Fischer et al. 2014a). According to standardized evaluation of sperm morphology, the classification of abnormalities was performed using specific categories (1. loose heads, 2 . other head abnormalities, 3 . acrosome abnormalities, 4. midpiece abnormalities, 5 . tail abnormalities) in order of priority (WHO 2010).

Statistical analysis: In accordance to the study design each pooled semen sample formed a statistical unit in the analysis. Statistically significant differences in mean for sperm motility parameters (MOT and PMOT), sperm viability values and sperm morphology using the different semen additives were tested based on two- or three-factorial analysis of variance (ANOVA) with repeated measures using the program BMDP2V from the statistical software package BMDP (Dixon 1993). To obtain nearly normal distributions of the analyzed variables, in morphology analysis an arcsine transformation of the data was performed prior to the analysis. Correlation was assessed using the Pearson correlation coefficient ( $\mathrm{r}$ ). In general, a significance level of $\alpha=0.05$ was used, so $p$-values less or equal to 0.05 indicated statistical significant effects.

\section{RESULTS}

Initial semen analysis and osmolality measurements: The time interval between the commencement of semen collection and the beginning of the initial semen analysis did not exceed 41 minutes.
Volume reached from 0.1 to $19.4 \mu \mathrm{l}(\mathrm{n}=262 ; \tilde{x}=2.20 \mu \mathrm{l}$; $\mathrm{Q} 1=1.00, \mathrm{Q} 3=4.125$ ) while in $38.2 \%$ of the samples semen color was between grayish and whitish and in $31.3 \%$ of the samples transparent. Median sperm density in the capillary tube was $3.5(\mathrm{n}=262 ; \mathrm{Q} 1=2.5$, $\mathrm{Q} 3=4.0$; range: 0 to 5 ). Mean estimated sperm motility in the microcapillary tube was $2.39 \pm 1.19(\mathrm{n}=262 ; \bar{x} \pm$ SD; range: 0 to 4 ). Sperm concentration ranged between 30,000 and 5,950,000 spermatozoa/ $\mu \mathrm{l}(\mathrm{n}=51 ; \tilde{x}=$ 350,000; $\mathrm{Q} 1=121,500, \mathrm{Q} 3=740,000)$, while measurements of $\mathrm{pH}$ revealed a range of $\mathrm{pH}$ from 6.4 to $8.5(\mathrm{n}=70 ; \bar{x} \pm \mathrm{SD}=7.42 \pm 0.42)$ in individual and $\mathrm{a}$ range of osmolality from 290 to $320 \mathrm{mOsm} / \mathrm{kg}(\mathrm{n}=9 ; \bar{x}$ $\pm \mathrm{SD}=298.62 \pm 9.56$ ) in pooled semen samples.

Adjustment of semen extenders: Semen extenders 1 to 3 were adjusted according to $\mathrm{pH}$ and osmolality values of the semen samples. The final composition after adjustment of the three semen extenders is shown in Table 1. All modifications of semen extenders from the original description are indicated by bold italic font. To guarantee comparability to previous studies $\mathrm{pH}$ (range: 4.9 to $6.13 ; \bar{x} \pm \mathrm{SD}=5.55 \pm 0.41$ ) and osmolality (range: 304 to $337 \mathrm{mOsm} / \mathrm{kg} ; \bar{x} \pm \mathrm{SD}=319.22 \pm 10.43$ ) of $1 \% \mathrm{G}$ were not adjusted.

Evaluation of semen extenders: By partitioning of the 16 pooled semen samples 64 samples were investigated for sperm motility, sperm viability and sperm morphology. The results of the global comparison of semen extenders, concentrations and observation time by three-way ANOVA with repeated measures in respect to time is provided in Table 2 .

Motility analysis: The global mean comparison revealed significant differences between extenders and between time (both $\mathrm{p}<0.0001$ ) while the differences between concentration were barely not significant $(\mathrm{p}=0.08)$ and all interactions were not statistically significant (Table 2). Over the investigation period of 120 minutes a decline in sperm motility (MOT and PMOT) was detected in the control samples as well as in all samples using semen extenders in each dilution (Tables 3 \& 4). Modified SE 1 in 1:4 dilution initially started with a higher $(\mathrm{p}<0.05)$ MOT ( $\bar{x} \pm \mathrm{SD}=77.31 \% \pm 7.01 \%$ ) value compared to the control and all other semen extenders in both dilutions (Table 3 ). Similar results were observed in initial PMOT $(\bar{x} \pm \mathrm{SD}=$ $70.74 \% \pm 7.82 \%$ ) (Table 4 ). Pairwise comparison of the 
different semen extenders with $1 \%$ G revealed SE 1 in 1:4 dilution to maintain MOT and PMOT better than $1 \% \mathrm{G}(\mathrm{p}<$ 0.01). Additionally, PMOT, but not MOT was maintained better by SE 1 in 1:8 dilution and SE 3 in 1:4 dilution compared to $1 \% \mathrm{G}(\mathrm{p} \leq 0.01)$ (Table 5). The comparison of both dilutions (1:4 and 1:8) within SE 1 showed differences in PMOT ( $<<0.05)$, but not in MOT ( $p>0.05)$. Again, 1:4 dilution achieved better results.

Table 2. Resulting p-values from the three-way ANOVA with repeated measures in respect to time; here: global comparison.

\begin{tabular}{|c|c|c|c|c|c|c|c|c|}
\hline & \multirow{2}{*}{ Variable } & \multicolumn{3}{|c|}{ main effects (p-value) } & \multicolumn{4}{|c|}{ interaction effects (p-value) } \\
\hline & & SE & $\mathrm{c}$ & $\mathrm{t}$ & SE x c & SE $x \mathrm{t}$ & $\mathrm{cxt}$ & SE $\times c \times t$ \\
\hline & MOT & $<0.0001$ & 0.0803 & $<0.0001$ & 0.6429 & 0.5114 & 0.1303 & 0.5630 \\
\hline & PMOT & $<0.0001$ & 0.0072 & $<0.0001$ & 0.3166 & 0.4152 & 0.1558 & 0.8506 \\
\hline & Viability & $<0.0001$ & 0.8077 & $<0.0001$ & 0.8961 & 0.5662 & 0.0884 & 0.4643 \\
\hline $\mathrm{M}$ & normal & $<0.0001$ & 0.0651 & 0.0003 & 0.0610 & 0.2421 & 0.4525 & 0.1540 \\
\hline $\begin{array}{l}\mathrm{o} \\
\mathrm{r}\end{array}$ & $\begin{array}{c}\text { Acrosome } \\
\text { abnormalities }\end{array}$ & 0.2514 & 0.1114 & 0.8845 & 0.8892 & 0.6415 & 0.9614 & 0.4499 \\
\hline $\begin{array}{l}\mathrm{p} \\
\mathrm{h}\end{array}$ & $\begin{array}{c}\text { Head } \\
\text { abnormalities }\end{array}$ & 0.0017 & 0.3772 & 0.0216 & 0.5464 & 0.9238 & 0.9816 & 0.9004 \\
\hline $\begin{array}{l}0 \\
1\end{array}$ & $\begin{array}{c}\text { Midpiece } \\
\text { abnormalities }\end{array}$ & 0.2062 & 0.3276 & 0.4114 & 0.0312 & 0.7616 & 0.4649 & 0.6417 \\
\hline $\begin{array}{l}\mathrm{o} \\
\mathrm{g}\end{array}$ & $\begin{array}{c}\text { Tail } \\
\text { abnormalities }\end{array}$ & 0.1044 & 0.2270 & 0.0021 & 0.4406 & 0.1195 & 0.1709 & 0.1570 \\
\hline $\mathrm{y}$ & $\begin{array}{c}\text { Multiple } \\
\text { abnormalities }\end{array}$ & 0.0648 & 0.7190 & 0.8837 & 0.7190 & 0.4524 & 0.9833 & 0.7510 \\
\hline
\end{tabular}

Abbreviations: SE, semen extender; c, concentration; t, time; x, interaction; MOT, total motility; PMOT, progressive motility.

Table 3. Sperm motility (MOT) in percent by comparison of different semen extenders and dilutions (n=64; \pm SD).

\begin{tabular}{cccccccc}
\hline Evaluation time & $1 \%$ G (1:5) & SE 1 (1:4) & SE 1 (1:8) & SE 2 (1:4) & SE 2 (1:8) & SE 3 (1:4) & SE 3 (1:8) \\
\hline $0 \mathrm{~min}$ & $56.63 \pm 13.57$ & $77.31 \pm 7.01$ & $65.00 \pm 10.68$ & $52.61 \pm 10.48$ & $49.87 \pm 14.75$ & $64.17 \pm 9.92$ & $60.46 \pm 5.68$ \\
$30 \mathrm{~min}$ & $56.36 \pm 17.34$ & $74.11 \pm 9.35$ & $62.89 \pm 13.39$ & $52.14 \pm 6.01$ & $49.52 \pm 12.03$ & $64.25 \pm 9.11$ & $61.66 \pm 8.13$ \\
$60 \mathrm{~min}$ & $48.88 \pm 14.49$ & $68.28 \pm 9.50$ & $62.31 \pm 13.04$ & $47.84 \pm 5.68$ & $41.64 \pm 14.10$ & $59.34 \pm 6.19$ & $56.24 \pm 9.76$ \\
$90 \mathrm{~min}$ & $45.27 \pm 13.72$ & $63.55 \pm 11.07$ & $56.14 \pm 12.09$ & $44.53 \pm 2.98$ & $38.43 \pm 15.82$ & $54.05 \pm 6.89$ & $49.80 \pm 12.04$ \\
$120 \mathrm{~min}$ & $37.03 \pm 16.65$ & $59.14 \pm 9.69$ & $54.31 \pm 12.06$ & $38.15 \pm 4.79$ & $36.45 \pm 13.56$ & $44.72 \pm 7.95$ & $46.76 \pm 12.26$ \\
\hline
\end{tabular}

Abbreviations: G, glucose-Ringer's solution; SE, semen extender.

Table 4. Progressive sperm motility (PMOT) in percent by comparison of different semen extenders and dilutions (n=64; \pm SD).

\begin{tabular}{cccccccc}
\hline Evaluation time & $1 \% \mathrm{G}(1: 5)$ & SE 1 (1:4) & SE 1 (1:8) & SE 2 (1:4) & SE 2 (1:8) & SE 3 (1:4) & SE 3 (1:8) \\
\hline $0 \mathrm{~min}$ & $41.89 \pm 15.00$ & $70.74 \pm 7.82$ & $55.03 \pm 10.06$ & $40.69 \pm 9.17$ & $37.90 \pm 14.57$ & $54.04 \pm 11.34$ & $48.13 \pm 11.32$ \\
$30 \mathrm{~min}$ & $41.13 \pm 16.27$ & $65.93 \pm 9.32$ & $50.66 \pm 13.67$ & $38.93 \pm 4.14$ & $36.23 \pm 13.40$ & $53.66 \pm 7.23$ & $48.82 \pm 8.83$ \\
$60 \mathrm{~min}$ & $33.75 \pm 12.09$ & $59.42 \pm 9.45$ & $48.70 \pm 12.65$ & $34.69 \pm 3.62$ & $30.28 \pm 12.65$ & $47.43 \pm 6.34$ & $41.81 \pm 9.02$ \\
$90 \mathrm{~min}$ & $30.87 \pm 10.21$ & $54.07 \pm 10.25$ & $41.09 \pm 10.49$ & $31.05 \pm 6.78$ & $23.69 \pm 13.53$ & $41.48 \pm 6.79$ & $35.62 \pm 7.17$ \\
$120 \mathrm{~min}$ & $21.82 \pm 13.21$ & $47.35 \pm 11.00$ & $41.10 \pm 12.02$ & $22.77 \pm 8.86$ & $20.76 \pm 11.44$ & $30.42 \pm 7.38$ & $29.42 \pm 8.33$ \\
\hline
\end{tabular}

Abbreviations: $\mathrm{G}=$ glucose-Ringer's solution; $\mathrm{SE}=$ semen extender.

Table 5. Resulting p-values from the two-way ANOVA with repeated measures in respect to time; here: pairwise comparison of SE's with $1 \%$ glucose-Ringer's solution.

\begin{tabular}{ccccccc}
\hline p-value & SE 1 (1:4) & SE 1 (1:8) & SE 2 (1:4) & SE 2 (1:8) & SE 3 (1:4) & SE 3 (1:8) \\
\hline Total motility & 0.0014 & 0.0529 & 0.7287 & 0.3487 & 0.1206 & 0.2651 \\
Progressive motility & $<0.0001$ & 0.0073 & 0.9476 & 0.4185 & 0.0129 & 0.1252 \\
Viability & 0.0028 & 0.0045 & 0.8983 & 0.9707 & 0.1725 & 0.3086 \\
\hline
\end{tabular}

Abbreviation: SE, semen extender. 
Viability analysis: The comparison of the percentage of viable spermatozoa counted in 46 eosin B-smears and 46 fluorescence stains SYBR $®$ Green/propidium iodide demonstrated a strong correlation of both evaluation methods $(\mathrm{n}=46 ; \mathrm{r}=0.893 ; \mathrm{p}<0.001)$. However, due to volume limitation, the remaining samples had to be stained using eosin B only (Figure 1 and Table 6). Pairwise comparison of the different semen extenders with $1 \%$ G showed that only SE 1 obtained higher viability values $(p<0.05)$. The comparison between SE 1 (1:4) and SE 1 (1:8) did not point out any differences $(p>0.05)$.

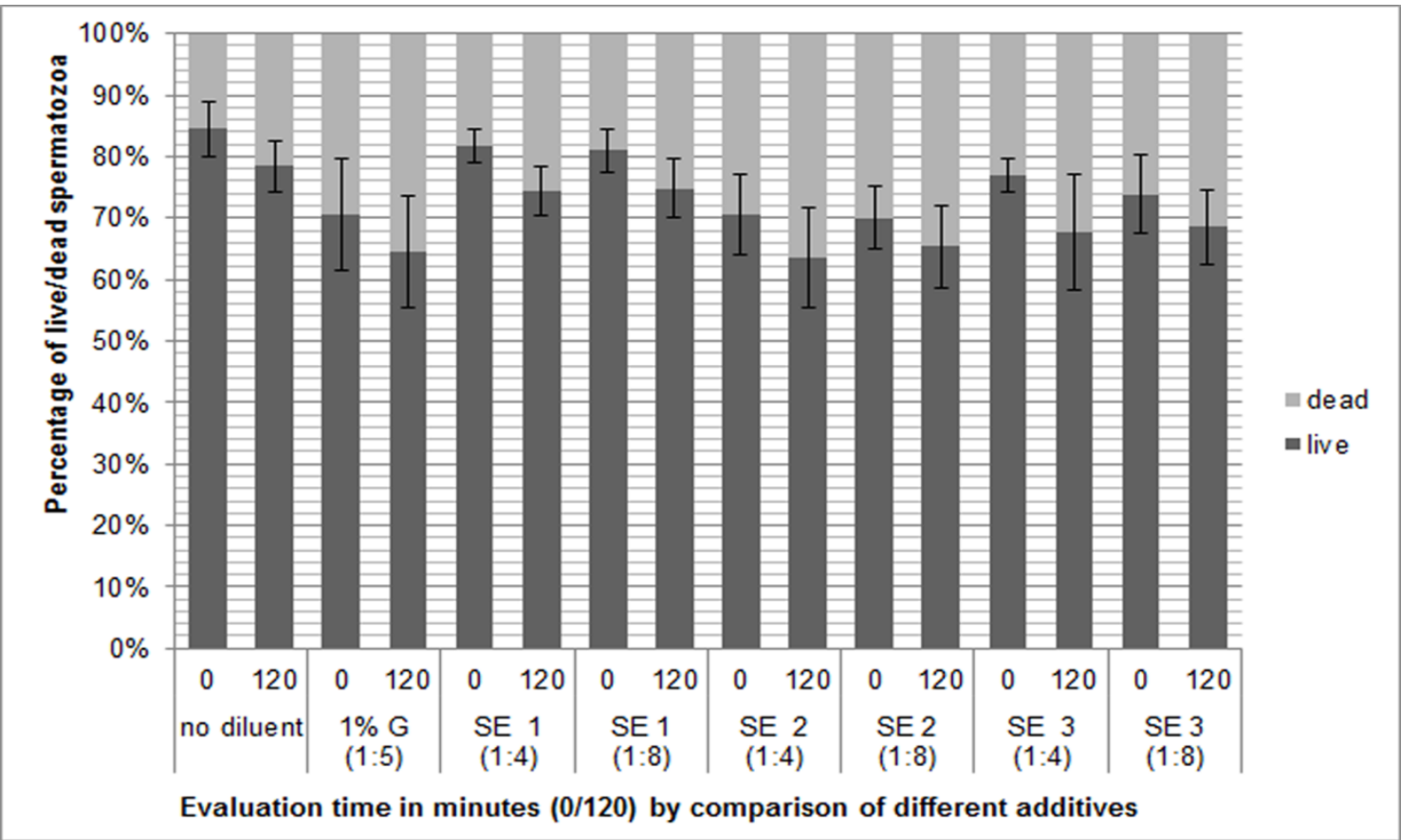

Figure 1. Mean viability (including standard deviation) in eosin B smears by comparison of pure semen samples and different semen extenders in different dilutions $(n=140 ; \pm S D)$.

Abbreviations: G, glucose-Ringer's solution; SE, semen extender.

Table 6. Mean sperm viability (eosin B) in percent by comparison of the different semen extenders ( $\mathrm{n}=64 ; \pm$ SD).

\begin{tabular}{|c|c|c|c|c|c|c|c|c|}
\hline evaluation time & no diluent & $1 \%$ G (1:5) & SE $1(1: 4)$ & SE $1(1: 8)$ & SE $2(1: 4)$ & SE 2 (1:8) & SE $3(1: 4)$ & SE 3 (1:8) \\
\hline $0 \mathrm{~min}$ & $84.45 \pm 4.42$ & $70.53 \pm 8.98$ & $81.69 \pm 2.78$ & $81.00 \pm 3.45$ & $70.50 \pm 6.63$ & $70.06 \pm 5.16$ & $77.00 \pm 2.79$ & $73.88 \pm 6.31$ \\
\hline $120 \mathrm{~min}$ & $78.45 \pm 4.00$ & $64.56 \pm 9.15$ & $75.25 \pm 3.81$ & $74.81 \pm 4.69$ & $63.69 \pm 8.04$ & $65.31 \pm 6.76$ & $67.75 \pm 9.32$ & $68.50 \pm 5.95$ \\
\hline
\end{tabular}

Abbreviations: G, glucose-Ringer's solution; SE, semen extender.

Morphology analysis: Morphological evaluation of 200 spermatozoa in each of 140 stains revealed multiple changes in cockatiel spermatozoa (Figure 2). Taken all together, mainly the tail region $(34.8 \%)$ and the head region $(21.3 \%)$ were morphologically altered, followed by abnormalities in the acrosome (1.99\%) and midpiece section $(1.6 \%)$. In $9.83 \%$ of the morphological abnormal spermatozoa multiple abnormalities occurred within one spermatozoon. A wide range $(10 \%$ to $61 \% ; \bar{x} \pm \mathrm{SD}=$ $30.40 \% \pm 13.13 \%$ ) of morphologically normal spermatozoa (MNS) was found. Morphology was significantly influenced by the different semen extenders and evaluation times (Table 7). The percentage of MNS depended on the utilisation of the different semen extenders and the investigation times ( $p<0.0001)$ (Table 7). Again, experimentally modified SE 1 in 1:4 dilution achieved a higher amount of MNS. Statistical analysis revealed that abnormalities concerning head abnormalities were influenced by the use of the different SE $(p<0.05)$ but not by storage time, whereas SE 1 showed the least rate of those abnormalities. However, tail abnormalities were not influenced by the different semen extenders $(p>0.05)$ but by time $(p<0.001)$. Acrosome, midpiece and multiple abnormalities were neither influenced by semen extender, nor by storage time ( $p>0.05)$. In general, none of the morphological characteristics was significantly influenced by treatment by time interaction. 


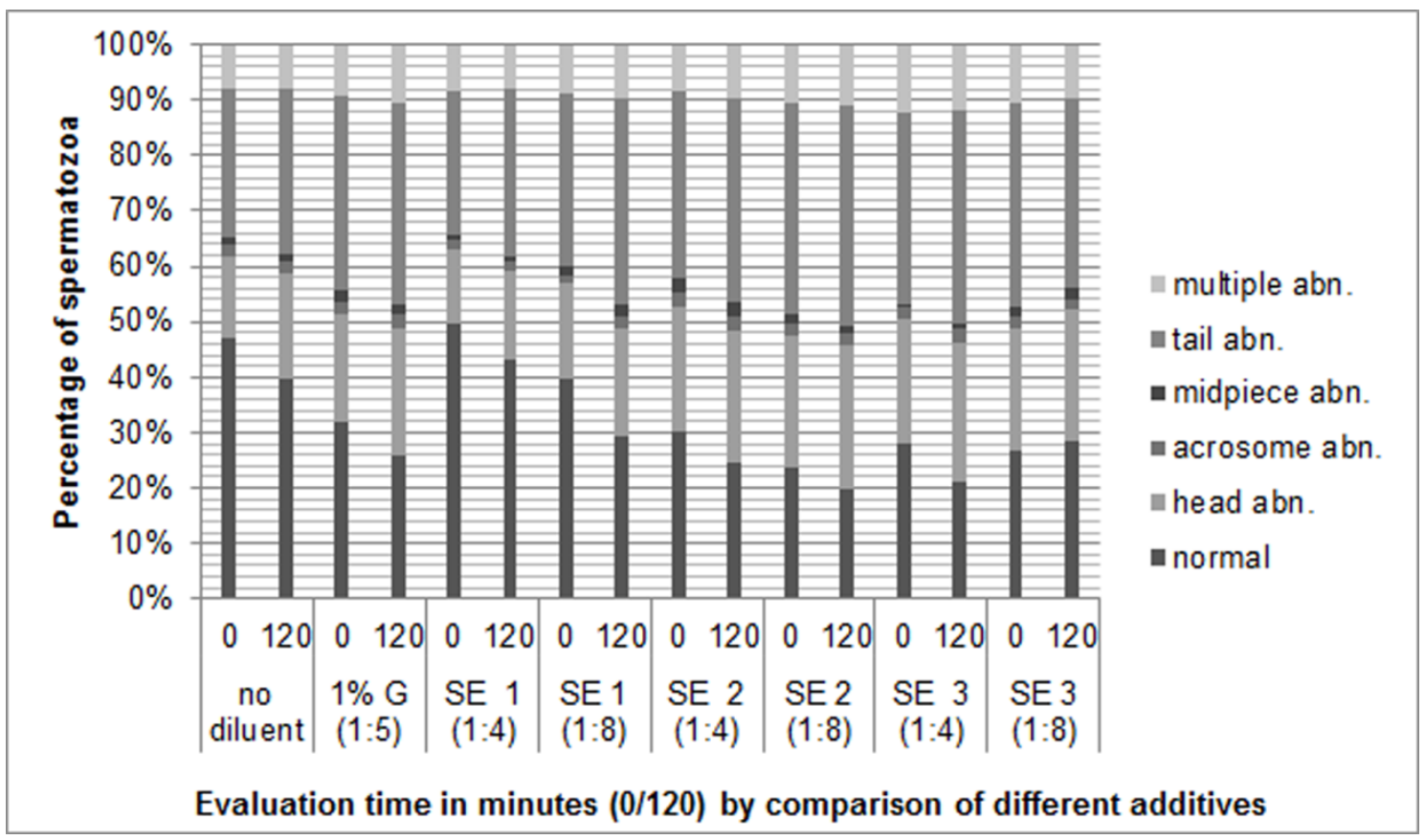

Figure 2. Graphical presentation of mean sperm morphology (time 0 and 120) in semen stains by comparison of different additives $(n=140)$.

Abbreviations: G, glucose-Ringer's solution; SE, semen extender; abn., abnormality.

Table 7. Resulting p-values from a two-way ANOVA with repeated measures in respect to time; here: sperm morphology.

\begin{tabular}{ccccccc}
\hline p-value & Normal & Head abn. & Acrosome abn. & Midpiece abn. & Tail abn. & Multiple abn. \\
\hline Treatment & $<0.0001$ & 0.0214 & 0.4102 & 0.0956 & 0.2247 & 0.1430 \\
Time & $<0.0001$ & 0.0036 & 0.9274 & 0.6613 & 0.0008 & 0.5960 \\
Interaction treatment by time & 0.3173 & 0.9701 & 0.8853 & 0.5366 & 0.0980 & 0.6990 \\
\hline
\end{tabular}

Abbreviation: abn., abnormality.

\section{DISCUSSION}

In our study, SE 1 allowed higher MOT and PMOT than previously used ones in psittacine AR. Before, 1\% G solution was reported to maintain sperm motility the best (Stelzer 2004), which could not be confirmed in this study. Firstly, our modified SE 1 did start with a higher initial PMOT ( $\bar{x} \pm \mathrm{SD}=70.74 \% \pm 7.82 \%$ ) than $1 \% \mathrm{G}$ diluted cockatiel semen in the previous study (approx. 61\%). Secondly, it also retained PMOT over a 120 minutes investigation period remarkably higher compared to the best dilution of previous investigations (decrease approx. 56\%) (Stelzer 2004). Additionally, semen osmolality values have been investigated for the first time in psittacines and impacts of the different semen extenders on sperm viability and morphology were evaluated. Usually, semen samples are evaluated individually to exclude interferences between spermatozoa of different males. Due to the little volume obtained from the cockatiels, detailed studies into the course of semen quality were only possible with pooled semen samples. Therefore, a potential impairment of semen quality in the consequence of sperm competition interactions cannot be excluded in the present study. Motility analysis of cockatiel semen diluted with 1\% G revealed an average MOT and PMOT in the range of previous studies (Fischer et al. 2014b), although it did neither boast best results concerning sperm motility (MOT and PMOT), nor viability compared to the used SE 1 in our study. In budgerigars the addition of three different semen extenders was subjectively evaluated judging half-life period and quality $(+-+++)$ of budgerigar sperm movement (Behncke 2002). 1\% G maintained MOT with constant quality (++) over a period of several minutes better than Ringer's solution and $5 \%$ glucose solution. Similar findings were reported through comparing the effect of six different semen extenders on cockatiel sperm motility (Stelzer 2004), where $1 \%$ G retained PMOT over a 30 minute period between $40 \%$ and $60 \%$, followed by a linear decrease to below $10 \%$ within the next 90 minutes. Despite the 
distinct degradation, $1 \% \mathrm{G}$ was reported to achieve the best results in comparison with Ringer's solution and $5 \%$ glucose solution, as well as diluents described for poultry (Bechstedt et al. 1974, Schramm and Löhle 1984, Bakst and Dymo 2013). Lake diluent was reported to start with an estimated PMOT of $15 \%$ within the first ten minutes of investigation, followed by a decline to $0 \%$ during investigation. In a study on Hispaniolan parrots initial MOT values between $41 \%$ and $82 \%$ were subjectively estimated using Lake diluent as a semen extender (Brock 1991). It has to be mentioned that the comparability of these findings is limited, as they all affect different psittacine species. Distinctive values could consequently arise from various reasons like individual differences of the used animals, different methods of the semen extraction, different methods of semen treatment or varying time intervals between semen collection and investigation and cannot only be ascribed to influences of the semen extender. All motility values in previous studies have been estimated in broadly defined groups (Behncke 2002) or in decadic percent ranges (Stelzer 2004) while in our study motility values have been calculated, allowing elaboration. Nevertheless, both methods are highly observerdependent and need expert experience (Verstegen et al. 2002). Unfortunately, the little sample volumes were insufficient for a computer assisted semen analysis (CASA) and therefore had to be performed manually. Comparison of the percentage decline of PMOT within SE 1 during 120 minutes revealed a lower decrease in 1:8 dilution $(\Delta=13.93 \%)$ than in $1: 4$ dilution $(\Delta=23.39 \%)$, while initial PMOT was significantly higher in 1:4 dilution. This may be attributed to the relatively higher amount of nutrients and energy providers in 1:8 dilution guaranteeing a lower decrease in MOT and PMOT, which indicates that a higher dilution might be beneficial for the purpose of long-term storage. The contradictory outcome between our study and previous studies on psittacine semen extenders might most possibly be due to the distinct osmolality values and $\mathrm{pH}$ numbers of the used semen extender. In our study the three semen extenders were adjusted especially to cockatiel semen while $1 \%$ G remained unchanged to ensure better comparability to previous studies (Behncke 2002, Stelzer 2004, Fischer et al. 2014b). It cannot be excluded that the difference between mean $\mathrm{pH}$ and osmolality of cockatiel semen and 1\% G impaired sperm motility in this way. A previous study reported hypertonic semen extenders to unveil positive effects on turkey spermatozoa survival (Giesen and Sexton 1983). On the contrary, a reduction of osmolality below $200 \mathrm{mOsm} / \mathrm{kg}$ irreversibly harmed turkey and fowl spermatozoa (Bakst 1980). The worse results of $1 \% \mathrm{G}$ in comparison with the other semen extenders might be due to the osmolality differences between cockatiel seminal plasma values and $1 \% \mathrm{G}$ and the low $\mathrm{pH}$-value of $1 \% \mathrm{G}$. Strikingly, $\mathrm{pH}$-values measured in our study $(\mathrm{n}=70 ; \tilde{x}=$ 7.5; range: 6.4 to 8.0) differed from previous studies in cockatiels ( $\mathrm{n}=128 ; \tilde{x}=9.0$; range 8.0 to 9.5 ) (Stelzer 2004). In those studies more alkaline $\mathrm{pH}$-values have been measured, similar to values in budgerigars $(\mathrm{n}=$ $126 ; \bar{x} \pm \mathrm{SD}=8.37 \pm 0.24$; range: 8.1 to 9.0 ) (Behncke 2002) and monk parakeets (Myiopsitta monachus) ( $\mathrm{n}=$ 8; range: 8.05 to 8.5) (Anderson et al. 2002). However, our semen pH-values are not out of range of other psittacine species. Semen of Spix's macaws (Cyanopsitta spixii) ( $\mathrm{n}=31 ; \tilde{x}=7.0$; range: 6.4 to 8.0 ) (Fischer et al. 2014a), of cockatoos $(\tilde{x}=7.0$; range: 5.4 to 8.0$)$, of Amazon parrots $(\tilde{x}=7.3$; range: 5.7 to 8.0$)$, of other macaw species ( $\tilde{x}=6.8$; range: 5.4 to 7.8$)$ and of Eclectus parrots ( $\tilde{x}=7.0$; range: 5.4 to 7.8 ) (Bublat et al. 2017) was also pH-neutral or slightly alkaline, respectively. Although macroscopically contaminated samples (feces and urates) were excluded from further investigation, it cannot be ruled out that a contamination with transparent fluid (Nishiyama 1951), a lymp-like fluid which is part of the seminal plasma, occurred. Contamination with blood, feces and transparent fluid would increase the $\mathrm{pH}$-value, whereas a contamination with urates would decrease it. However, the same applies for other studies too, in which the exclusion of contaminated samples has not been mentioned by the authors in all studies. Moreover, differences due to the usage of different $\mathrm{pH}$ indicator strips should be considered.

Particularly minding usual cell death during future freezing and thawing procedures a viability of $\geq 70 \%$ at both investigation times $(0 ; 120 \mathrm{~min})$ was aimed at in the present study (Holt 2000). This was only fulfilled by SE 1 in both dilutions. Unfortunately, sperm viability after dilution has not been evaluated in psittacines before, rendering comparison with previous studies on psittacine semen impossible. Contrary to our expectations, the addition of ATP to SE 2 did not seem to have a similar positive influence on motility or viability 
of cockatiel spermatozoa as demonstrated on turkey and crane sperm (Blanco et al. 2011). However, in the mentioned study semen values were determined after thawing of semen and not for the purpose of short-time liquid storage as in the present study. Surprisingly, pure samples resulted in higher viability values after 120 minutes of storage than diluted ones, although we hypothesized it to be the other way around. As it is known that the quality of staining may be influenced by many factors, a possible reaction of the semen extenders with the staining solution might be an explanation for the misinterpretation as dead spermatozoa, thus leading to false low values.

In this study a relation between semen extenders, storage time and effects on sperm morphology have been investigated for the first time in psittacine species. During the time of storage, a decrease in live, morphologically normal spermatozoa and an increase in dead spermatozoa and spermatozoa with bent heads were observed in all semen extenders, which was in agreement with previous studies on fowl spermatozoa (Blesbois et al. 1999, Siudzinska and Lukaszewicz 2008). Our findings demonstrate that every semen extender seems to have a significant influence on abnormalities of the sperm head, a region which is known to be highly sensitive to osmotic variances (Bakst 1980). As this effect is suspected to be independent from storage time an optimization of semen extenders was regarded essential - even for very short storage time. In contrast, tail abnormalities did not show any dependence on the used semen extender in the present study but occurred significantly more frequent after prolonged storage time. This might be related to energy losses during storage. As acrosome and midpiece sections were not influenced by treatment or time these regions seem to be less sensitive. Morphological alterations are important because the percentage of viable, MNS has been strongly correlated to fertilization success $(r=0.66, p<0.01)$ in the domestic chicken (Blesbois et al. 2008). In this regard, various morphologic abnormalities are reported to have a negative impact on sperm velocity (Lüpold $e t$ al. 2009), while sperm motility (MOT and PMOT) are positively correlated with fertilization success (Birkhead et al. 1999, Froman et al. 1999, Blesbois et al. 2008). This underlines the importance to investigate sperm morphology in course of a proper evaluation of semen diluents. Moreover, this demonstrates that semen diluted with SE1 is most promising to achieve fertilization following $\mathrm{AI}$ if other influencing factors are not altering this.

\section{CONCLUSION}

The evaluation of semen quality is of great importance regarding the prediction of survival of spermatozoa during long-term storage and cryopreservation as well as for the prediction of fertilization success following AI (Blesbois et al. 2008). Frequently utilized in vitro quality tests for semen are the evaluation of sperm viability as well as the percentages of MNS and - most important motile spermatozoa (Birkhead et al. 1999, Froman 2000). Based on the current results, we conclude that our modified SE 1 had the least harmful effect on cockatiel spermatozoa and is therefore considered as the most appropriate semen extender for short time storage in cockatiels. Hopefully, this may be taken as a solid basis for cryopreservation of psittacine spermatozoa. However, species-specific differences in sperm metabolism must be considered and further investigations concerning basic semen parameters and effects of semen extenders on semen of different psittacine species are required.

\section{DECLARATION OF INTEREST}

The authors confirm that there are no conflicts of interest.

\section{REFERENCES}

Anderson, S. J., D. M. Bird, and M. D. Hagen. 2002. Semen characteristics of the quaker parakeet (Myiopsitta monachus). Zoo Biology 21:507-512. doi: 10.1002/zoo.10060

Arndt, T. 1996. The complete lexicon of parrots. 1st edition. Arndt-Verlag, Bretten, Germany.

Bakst, M. R. 1980. Fertilizing capacity and morphology of fowl and turkey spermatozoa in hypotonic extender. Journal of reproduction and fertility 60:121-127. doi: 10.1530/jrf.0.0600121

Bakst, M. R., and J. S. Dymo. 2013. Artificial Insemination in Poultry. In Success in Artificial Insemination Quality of Semen and Diagnostics Employed. InTech. doi: 10.5772/54918

Bechstedt, U., K. Lohle, and R. Schramm. 1974. Untersuchungen zur Verdünnung und Kurzzeitkonservierung von Hahnensperma. Monatshefte fur Veterinarmedizin 30:937 - 940.

Behncke, H. 2002. Spermagewinnung und untersuchung sowie endoskopische Beurteilung des Geschlechtsapparats in Abhängigkeit von der Spermaproduktion bei Psittaziden am Beispiel des 
Wellensittichs (Melopsittacus undulatus). Veterinärmedizinische Fakultät Universität Leipzig.

Birkhead, T. R., J. G. Martínez, T. Burke, and D. P. Froman. 1999. Sperm mobility determines the outcome of sperm competition in the domestic fowl. Proceedings. Biological sciences / The Royal Society 266:1759-1764. doi: 10.1098/rspb.1999.0843

Blanco, J., J. Long, G. Gee, A. Donoghue, and D. Wildt. 2008. Osmotic tolerance of avian spermatozoa: Influence of time, temperature, cryoprotectant and membrane ion pump function on sperm viability. Cryobiology 56:8-14. doi: 10.1016/j.cryobiol.2007.09.004

Blanco, J. M., J. A. Long, G. Gee, D. E. Wildt, and A. M. Donoghue. 2011. Comparative cryopreservation of avian spermatozoa: Benefits of non-permeating osmoprotectants and ATP on turkey and crane sperm cryosurvival. Animal Reproduction Science 123:242-248. doi: 10.1016/j.anireprosci.2010.12.005

Blanco, J. M., J. A. Long, G. Gee, D. E. Wildt, and A. M. Donoghue. 2012. Comparative cryopreservation of avian spermatozoa: Effects of freezing and thawing rates on turkey and sandhill crane sperm cryosurvival. Animal Reproduction Science 131:18. doi: 10.1016/j.anireprosci.2012.02.001

Blanco, J., D. Wildt, U. Hofle, W. Voelker, and A. Donoghue. 2009. Implementing artificial insemination as an effective tool for ex situ conservation of endangered avian species. Theriogenology 71:200-213. doi: 10.1016/j.theriogenology.2008.09.019

Blesbois, E., I. Grasseau, and D. Hermier. 1999. Changes in lipid content of fowl spermatozoa after liquid storage at 2 to 5 degrees C. Theriogenology 52:325-334.

Blesbois, E., I. Grasseau, F. Seigneurin, S. MignonGrasteau, M. Saint Jalme, and M. M. MialonRichard. 2008. Predictors of success of semen cryopreservation in chickens. Theriogenology 69:252-261. doi: 10.1016/j.theriogenology.2007.09.019

Brock, M. K. 1991. Semen Collection and Artificial Insemination in the Hispaniolan Parrot (Amazona ventralis). Journal of Zoo and Wildlife Medicine 22:107-114.

Bublat, A., D. Fischer, S. Bruslund, H. Schneider, S.
Meinecke-Tillmann, A. Wehrend, and M. Lierz. 2017. Seasonal and genera-specific variations in semen availability and semen characteristics in large parrots. Theriogenology 91:82-89. doi: 10.1016/j.theriogenology.2016.11.029

Collar, N. J., and S. H. M. Butchart. 2014. Conservation breeding and avian diversity: chances and challenges. International Zoo Yearbook 48:7-28. doi: 10.1111/izy.12039

Dixon, W. J. 1993. BMDP Statistical Software Manual, Volume 1 and 2. University of California Press, Berkeley, Los Angeles, London.

Fischer, D., D. Neumann, C. Purchase, T. Bouts, S. Meinecke-Tillmann, A. Wehrend, and M. Lierz. 2014a. The use of semen evaluation and assisted reproduction in Spix's macaws in terms of species conservation. Zoo Biology 33:234-244. doi: 10.1002/zoo.21129

Fischer, D., D. Neumann, A. Wehrend, and M. Lierz. 2014b. Comparison of conventional and computer-assisted semen analysis in cockatiels (Nymphicus hollandicus) and evaluation of different insemination dosages for artificial insemination. Theriogenology 82:613-20. doi: 10.1016/j.theriogenology.2014.05.023

Froman, D. P. 2000. Sperm Mobility: Phenotype in Roosters (Gallus domesticus) Determinedby Concentration of Motile Sperm and Straight Line Velocity. Biology of Reproduction 62:303-309. doi: 10.1095/biolreprod62.2.303

Froman, D. P., A. J. Feltmann, M. L. Rhoads, and J. D. Kirby. 1999. Sperm mobility: A primary determinant of fertility in the domestic fowl (Gallus domesticus). Biology of reproduction 61:400-405. doi: 10.1095/biolreprod61.2.400

Giesen, A. F. and T. J. Sexton. 1983. Beltsville Poultry Semen Extender: 7. Comparison of Commercial Diluents for Holding Turkey Semen Six Hours at 15 C,. Poultry Science 62:379-381. doi: $10.3382 /$ ps.0620379

Holt, W. V. 2000. Basic aspects of frozen storage of semen. Animal Reproduction Science 62:3-22. doi: 10.1016/S0378-4320(00)00152-4

Iaffaldano, N., M. P. Rosato, A. Manchisi, and G. Centoducati. 2010. Comparison of different extenders on the quality characteristics of turkey semen during storage. Italian Journal of Animal Science. doi: 10.4081/ijas.2005.2s.513 
IUCN 2014. The IUCN Red List of Threatenend Species. (Online.) Available at http://www.iucnredlist.org/.

Lake, P. E., and J. M. Stewart. 1978. Preservation of fowl semen in liquid nitrogen-an improved method. British Poultry Science 19:187-194. doi: 10.1080/00071667808416462

Lierz, M., M. Reinschmidt, H. Müller, M. Wink, and D. Neumann. 2013. A novel method for semen collection and artificial insemination in large parrots (Psittaciformes). Sci. Rep. 3:2066. doi: 10.1038/srep02066

Lüpold, S., S. Calhim, S. Immler, and T. R. Birkhead. 2009. Sperm morphology and sperm velocity in passerine birds. Proceedings of the Royal Society 276 no. 16:1157-1181. doi: 10.1098/rspb.2008.1645

Marvan, F., O. Rob, and E. Janecková. 1981. Die Klassifikation morphologischer Spermienanomalien bei Gantern. Zuchthygiene 16:176-183.

Neumann, D., E. F. Kaleta, and M. W. Lierz. 2013. Semen collection and artificial insemination in Cockatiels (Nymphicus hollandicus) - A potential model for Psittacines. Tierarztliche Praxis 41 (K):101-105.

Nishiyama, H. 1951. Studies on the physiology of reproduction in the male fowl III. On the addition of transparent fluid to the cock's semen. Science Bulletin of the Faculty of Agriculture, Kyushu University 13:377 - 387.

Quinn, J. P., and W. H. Burrows. 1936. Artificial insemination in fowls. The Journal of Heredity:3138.

Salamon, S., and W. M. C. Maxwell. 2000. Storage of ram semen. Animal Reproduction Science 62:77-111. doi: 10.1016/S0378-4320(00)00155-X

Samour, J. H. 2002. The Reproductive Biology of the Budgerigar (Melopsittacus undulatus): Semen Preservation Techniques and Artificial Insemination Procedures. Journal of Avian Medicine and Surgery 16:39-49. doi:10.1647/1082-6742(2002)016[0039:TRBOT B]2.0.CO;2

Samour, J. H., J. A. Markham, H. D. M. Moore, and P. F. Watson. 1988. Semen cryopreservation and artificial insemination in budgerigars (Melopsittacus undulatus). Journal of Zoology 216:169-176. doi: 10.1111/j.14697998.1988.tb02422.x

Schramm, G. P., and K. Löhle. 1984. Verdünnung und Flüssigkonservierung des Spermas - eine Möglichkeit zur Erhöhung der Effektivität der Zuchtarbeit und Rationalisierung der künstlichen Besamung beim Geflügel. Monatshefte fur Veterinarmedizin 40:135-138.

Sexton, T. J. 1977. A new poultry semen extender. 1. Effects of extension on the fertility of chicken semen. Poultry science 56:1443-1446. doi: $10.3382 /$ ps. 0561443

Siudzinska, A., and E. Lukaszewicz. 2008. Effect of Semen Extenders and Storage Time on Sperm Morphology of Four Chicken Breeds. The Journal of Applied Poultry Research 17:101-108. doi: 10.3382/japr.2007-00048

Snyder, N., P. McGowan, J. Gilardi, and A. Grajal. 2000. Parrots: status survey and conservation action plan 2000 - 2004. International Union for Conservation of Nature and Natural Resources, Gland, Switzerland and Cambridge, UK.

Stelzer, G. 2004. Spermagewinnung, -untersuchung und flüssigkonservierung bei verschiedenen Papageienvögeln (Psittaciformes). Veterinärmedizinische Fakultät der Universität Leipzig.

Verstegen, J., M. Iguer-Ouada, and K. Onclin. 2002. Computer assisted semen analyzers in andrology research and veterinary practice. In Theriogenology. pp. 149-179. doi: 10.1016/S0093-691X(01)00664-1

WHO 2010. WHO laboratory manual for the examination and processing of human semen. 5th edition. World Health Organization Press, Geneva, Switzerland.

Wright, T. F., C. A. Toft, E. Enkerlin-Hoeflich, J. GonzalezElizondo, M. Albornoz, A. Rodríguez-Ferraro, F. Rojas-Suárez, V. Sanz, A. Trujillo, S. R. Beissinger. 2001. Nest Poaching in Neotropical ParrotsSaqueo de Nidos de Loros Neotropicales. Conservation Biology 15:710-720. doi: 10.1046/j.15231739.2001.015003710.x 
Publisher's note: EScience Press remains neutral with regard to jurisdictional claims in published maps and institutional affiliations.

CC (i) Open Access This article is licensed under a Creative Commons Attribution 4.0 International License, which permits use, sharing, adaptation, distribution and reproduction in any medium or format, as long as you give appropriate credit to the original author(s) and the source, provide a link to the Creative Commons license and indicate if changes were made. The images or other third-party material in this article are included in the article's Creative Commons license, unless indicated otherwise in a credit line to the material. If material is not included in the article's Creative Commons license and your intended use is not permitted by statutory regulation or exceeds the permitted use, you will need to obtain permission directly from the copyright holder. To view a copy of this license, visit http://creativecommons.org/licenses/by/4.0/.

(C) The Author(s) 2018. 